\title{
Economic analysis of oral posaconazole prophylaxis in acute myeloid leukemia during remission induction in Turkey
}

\author{
(D) Elif Gulsum Umit, (D) Mehmet Baysal, (D) Hakki Onur Kirkizlar, (D) Ahmet Muzaffer Demir \\ Department of Hematology, Trakya University Faculty of Medicine, Edirne, Turkey
}

\begin{abstract}
OBJECTIVE: Invasive fungal infections (IFI) are important and trending causes of mortality in patients with acute leukemia, especially during the remission induction.

METHODS: In this study, 225 patients who were diagnosed with acute myeloid leukemia (AML) and undergoing intensive treatment for remission induction were enrolled in a retrospective manner.

RESULTS: Within the whole group, which consisted of 225 patients, 90 patients received prophylactic antifungal treatment (PAT) (40\%), while 135 patients did not (60\%) receive. The mean cost of hospitalization was 9.151,6 (2.872,6-20.483,3) US dollars. Gender distribution and mean ages of groups were similar. One hundred fourteen patients not on PAT (84.4\%) and five patients on PAT (5.5\%) received intravenous antifungal treatment. Thirty-two of the patients who were not on PAT $(23.7 \%)$ and 11 of the patients on PAT died during remission induction (12.22\%). The mean day of the hospitalization was 22.61 days for the patients on PAT and 33.89 days for the patients who were not on PAT. In patients on PAT, the mean number of transfused platelet units was six (0-9), while 12.51 (4-43) units for patients who were not on PAT.

CONCLUSION: In our study, the oral suspension form of posaconazole was observed to be cost-effective to prevent IFI with a significant decrease in mortality during remission induction treatment.

Keywords: Acute myeloid leukemia; invasive fungal infection.

Cite this article as: Umit EG, Baysal M, Kirkizlar HO, Demir AM. Economic analysis of oral posaconazole prophylaxis in acute myeloid leukemia during remission induction in Turkey. North Clin Istanb 2020;7(3):222-225.
\end{abstract}

Tnvasive fungal infections (IFI) are important and trending causes of mortality in patients with acute myeloid leukemia (AML). The patients are demonstrated to bear the highest risk of IFI during remission induction and allogenous stem cell transplantation (ASCT) due to cytotoxic chemotherapy, prolonged severe neutropenia, loss of innate immunity (gastrointestinal mucosal barrier and microbiota) and long term exposure to broad-spectrum antibiotics leading to a selective and resistant microbial environment [1].

With the trend towards primary prophylaxis in highrisk patients, which are defined as AML patients receiv- ing remission induction treatment and patients who are undergoing ASCT, the choice of treatment has been the topic of various studies [1-4]. First fluconazole, then voriconazole and posaconazole have been investigated as suggested choice of prophylactic antifungal treatment. In our country, oral suspension form was the first form of posaconazole available and approved for reimbursement for primary prophylaxis in patients with high-risk AML and MDS by 2010 and tablet and intravenous form have recently been in market, by 2017 . Use of posaconazole for IFI prophylaxis starting with or just after cytotoxic

Received: April 25, 2019 Accepted: August 01, 2019 Online: April 08, 2020

Correspondence: Dr. Elif Gulsum UMIT. Trakya Universitesi Tip Fakultesi, Hematoloji Anabilim Dali, Balkan Yerleskesi, 22030 Edirne, Turkey.

Tel: +90 2842357641 - 4616/1116 e-mail: elifgumit@trakya.edu.tr

(c) Copyright 2020 by Istanbul Provincial Directorate of Health - Available online at www.northclinist.com 
chemotherapy until neutrophyl recovery has been associated with a significant decrease in IFI and overall mortality [5]. In addition to the positive perspective of prophylactic antifungal treatment (PAT), there are certain concerns of this approach, including overuse of these agents, resistance, toxicity, polypharmacy and costs. These concerns of PAT with posaconazole have been investigated in certain countries [6-8].

In our study, we aimed to evaluate the economic evaluation of the effectiveness of oral posaconazole in suspension form for the indication of PAT in patients with AML who are receiving intensive treatment for remission induction.

\section{MATERIALS AND METHODS}

Two hundred twenty-five patients who were diagnosed with acute myeloid leukemia (AML) between 20102016 in the Hematology Department of Trakya University, the tertiary referral hospital of the region enrolled in this study in a retrospective manner. Ethical consent was obtained from the local ethical committee with the number 2017/916 in 06.09.2017. All patients received standard care for first-line remission induction of AML, also called intensive treatment (idarubicin $12 \mathrm{mg} / \mathrm{m}^{2}$ for three days and cytarabine $100 \mathrm{mg} / \mathrm{m}^{2} 24 \mathrm{~h}$ infusion for seven days).

Patients receiving non-intensive treatment, secondline remission induction treatment or palliative care were not included in this study.

Direct health expenses from hospital management perspective, including days of hospitalization, number of CT scans for detection of IFI, development of complications, number of platelet apheresis infusions, mortality during remission induction treatment and total inpatient hospital costs, were recorded from hospital files. Days of hospitalization started with the initial diagnosis workup of AML covers the period of remission induction chemotherapy and the neutropenic period following chemotherapy. Discharge from the hospital depended on the clinical condition of each patient and the clinical approach stated that any patient who had stable platelet counts above $20 \times 10^{9}$ without transfusion, neutrophil count above $500 \times 10^{9}$ and without infection were discharged. Evaluation of the remission status is performed after the post-infection improvement period. The benefits of the intervention in question included cost reductions in patients who received posaconazole.
TABLE 1. Antifungal drugs and costs in Turkey

\begin{tabular}{|c|c|c|c|}
\hline Name of drug & $\begin{array}{l}\text { Box price for } \\
\text { reimbursement }\end{array}$ & $\begin{array}{c}\text { Daily average } \\
\text { dosage }\end{array}$ & $\begin{array}{l}\text { Daily } \\
\text { cost }\end{array}$ \\
\hline Posaconazole (oral) & $263.12 \$$ & $600 \mathrm{mg}$ & $43.85 \$$ \\
\hline Voriconazole (IV) & $35.86 \$$ & $600 \mathrm{mg}$ & $107.26 \$$ \\
\hline Caspofungin (IV) & $123.74 \$$ & $50 \mathrm{mg}$ & $123.74 \$$ \\
\hline $\begin{array}{l}\text { Liposomal } \\
\text { amphotericin (IV) }\end{array}$ & $848.6 \$$ & $400 \mathrm{mg}$ & $677.09 \$$ \\
\hline
\end{tabular}

The definition of PAT is the use of posaconazole, 600 $\mathrm{mg} /$ daily in three divided doses, and in oral suspension form. All patients were strictly and repeatedly controlled to ingest posaconazole within the dietary regulations recommended by the manufacturer. Proton pump inhibitors were not used in any patients receiving posaconazole due to interference with bioavailability. As the regulator of reimbursement, Health Application Communiqué of Turkey has approved the use of posaconazole for PAT in patients with AML who are undergoing remission induction therapy or patients undergoing ASCT by 2010. The costs of available antimould antifungal drugs are summarized in Table 1 .

\section{Statistical Analysis}

All analyses were performed using IBM SPSS V20. Descriptive analysis, Chi-square, Fisher's exact test, the Mann-Whitney U test, Kruskal-Wallis analysis and for parametric variables, Student's t-test and ANOVA, for survival analysis, Kaplan Meier method were used. All significant parameters were re-assessed by logistical regression for statistical significance.

\section{RESULTS}

General Features of the Patients

Within the whole group that consisted of 225 patients, the mean age was 57.76 years $(20-68)$. One hundred one patients were female $(44.9 \%)$ and 124 were male (55.1\%). Ninety patients received PAT (40\%) and 135 patients did not receive PAT (60\%). Within the whole group, 43 patients died during remission induction treatment (19.1\%).

Regarding health expenses, the mean number of days for hospitalization was 29.36 (14-88) days. The mean 
TABLE2. Analysis of patients regarding the costs and benefits of antifungal prophylaxis

Total number
Total days of hospitalization
Number of transfused platelet apheresis units mean (range)
Number of ct scans for thorax
Patients treated for invasive fungal infection
Patients died during remission induction therapy
Cytogenetic profile of patients (good-intermediate-poor)
Total cost of remission induction treatment (US Dollars)

number of units of transfused thrombocyte apheresis was $9.9(0-43)$ units. The mean number of thorax CT scans during remission induction was $1.73(0-6)$. The mean cost of whole remission induction treatment was $9.151,6(2.872,6-20.483,3)$ US dollars.

\section{Comparisons}

As the patients were grouped as patients who received and did not receive PAT, gender distribution, and mean ages of groups were statistically similar (59 female patients in no-PAT group and 42 female patients in the PAT group, mean age 58.33 years in no-PAT group and 56.90 years in PAT group).

Development of IFI. Within the no-PAT group (total 135 patients), 114 patients $(84.4 \%)$ had to be treated with an intravenous large spectrum antifungal treatment while only five of the patients on PAT (5.5\%) received treatment for IFI $(p<0.005)$. These five patients who have been treated with the concern of breakthrough infection, thoracal-abdominal CT scans and bronchoalveolar lavage samples did not show any breakthrough fungal infection, four patients were observed to have neutropenic enterocolitis and one patient had probable Pneumocystis pneumonia.

Mortality. In this study, 32 of the no-PAT patients died during remission induction $(23.7 \%)$, while 11 of the patients who are on PAT died during remission induction $(12.22 \%)(p=0.021)$.

Hospital Expenses. Mean days of the hospitalization for remission induction treatment was 22.61 days for PAT patients and 33.89 days for no-PAT patients $(p<0.005)$. In patients on PAT, the mean number of transfused platelet units was six (0-9), while it was 12.51
(4-43) units for no-PAT patients $(p<0.005)$. The mean number of the CT scans in PAT group was $0.79(0-4)$, while it was $2.36(0-6)$ in the no-PAT group. And mean of the overall cost of remission induction treatment for PAT patients was $6.360,6(2.872,6-11.550)$ and 11.026 $(3.750-20.483,3)$ in the no-PAT group.

Between two groups, there were significant differences between groups regarding total days of hospitalization, number of transfused platelet apheresis units, number of CT scans for the thorax, death during remission induction and total cost of remission induction treatment in favor of the patients on PAT.

All significant data were analyzed using logistic regression analysis and observed as statistically significant. Cytogenetic analysis of patients regarding prognosis, in the PAT group, 14 patients were related with a good cytogenetic profile $[t(8.21)$, inv 16 and $t(15.17)], 61$ showed intermediate and 15 showed poor cytogenetic profile. In the non-PAT group, 11 patients showed good, 113 intermediate and 11 poor cytogenetic profiles, which were not statistically insignificant. Data regarding the comparison of PAT are summarized in Table 2.

\section{DISCUSSION}

With the introduction of new antifungal agents, strategies have changed from treatment to prevention. Guidelines for febrile neutropenia in oncologic patients have categorized the patients regarding the risk of infection and hematologic malignancies, as well as their treatments, have marked these patients as high-risk [1-4]. Particularly patients who are receiving remission induction therapy for AML and ASCT are expected to linger in the immunocompromised state for longer periods. 
Once an invasive fungal infection is started, managing the infection and its complications are much more challenging. According to the guidelines, posaconazole is strongly recommended with category 1 evidence, while voriconazole and fluconazole is strongly recommended with category $2 \mathrm{~B}$ evidence strength and micafungin and amphotericin B are weakly recommended $[2,4]$.

Regarding the economic evaluation of PAT, in the SEIFEM-2010 study, the cost-effectiveness of oral PAT was evaluated and posaconazole prophylaxis was observed to be related with higher overall survival and less costly from itraconazole [6]. Likewise, in the United States, posaconazole but tablet form was observed to be cost-effective in the prevention of the IFI compared to fluconazole and itraconazole $[7,8]$.

In our study, the oral suspension form of posaconazole was effective in preventing IFI with a significant decrease in mortality during remission induction treatment. Likewise, PAT with posaconazole was observed to be costbeneficial regarding the factors which may be regarded as both financial and nonfinancial measures including CT scans, platelet transfusion, hospitalization periods and cost-effective regarding the data of overall costs of hospitalization for remission induction treatment. With its limitations regarding adherence as oral suspension form, tablet form may overcome these limitations.

\section{Conclusion}

Cost-effectiveness is one of the primary concerns of every intervention in medicine. Although analysis of cost-effectiveness is not always simple, observations from daily practice and direct numbers from patient files caused a need for us to evaluate our humble observations. As a country where sources should be used effectively and prudently, this direct observation may be interpreted as oral prophylaxis for IFI is effective to reduce hospital expenses.

Ethics Committee Approval: Trakya University Clinical Research Ethics Committee granted approval for this study (date: 06.09.2017, number: 2017/916).
Conflict of Interest: No conflict of interest was declared by the authors.

Financial Disclosure: The authors declared that this study has received no financial support.

Authorship Contributions: Concept - EGU; Design - EGU, MB; Supervision - AMD; Fundings - EGU; Materials - EGU, MB; Data collection and/or processing - HOK, MB; Analysis and/or interpretation - EGU, AMD; Literature review - EGU; Writing - EGU; Critical review - EGU, AMD.

\section{REFERENCES}

1. Zhang R, Chen J, Huang H, Ma J, Meng F, Tang Y, et al. Primary fungal prophylaxis in acute leukemia patients with different risk factors: retrospective analysis from the CAESAR study. Int J Hematol 2017;106:221-8. [CrossRef]

2. Mellinghoff SC, Panse J, Alakel N, Behre G, Buchheidt D, Christopeit $\mathrm{M}$, et al. Primary prophylaxis of invasive fungal infections in patients with haematological malignancies: 2017 update of the recommendations of the Infectious Diseases Working Party (AGIHO) of the German Society for Haematology and Medical Oncology (DGHO). Ann Hematol 2018;97:197-207. [CrossRef]

3. Berking S, Doedens D, Horns H, Fiegl M, Ostermann H, Rieger CT. Antifungal prophylaxis in newly diagnosed AML patients-Adherence to guidelines and feasibility in a real life setting. Mycoses 2017;60:600-6. [CrossRef]

4. Wang ES. Guideline recommendations for the prophylaxis of invasive aspergillosis in AML. Clin Adv Hematol Oncol 2016;14:876-9.

5. Hachem R, Assaf A, Numan Y, Shah P, Jiang Y, Chaftari AM, et al. Comparing the safety and efficacy of voriconazole versus posaconazole in the prevention of invasive fungal infections in high-risk patients with hematological malignancies. Int J Antimicrob Agents 2017;50:384-8. [CrossRef]

6. Busca A, Lessi F, Verga L, Candoni A, Cattaneo C, Cesaro S, et al; on the behalf of the SEIFEM Group (Sorveglianza Epidemiologica Infezioni Fungine in Emopatie Maligne). SEIFEM 2010-E: economic evaluation of posaconazole for antifungal prophylaxis in patients with acute myeloid leukemia receiving induction chemotherapy. Leuk Lymphoma 2017;58:2859-64. [CrossRef]

7. Cámara R, Gozalbo I, Jurado M, Sanz J, Aragón B, Grau S. Cost-Effectiveness of Posaconazole Tablets for Invasive Fungal Infections Prevention in Acute Myelogenous Leukemia or Myelodysplastic Syndrome Patients in Spain. Adv Ther 2017;34:2104-19. [CrossRef]

8. Sung AH, Marcella SW, Xie Y. An update to the cost-effectiveness of posaconazole vs fluconazole or itraconazole in the prevention of invasive fungal disease among neutropenic patients in the United States. J Med Econ 2015;18:341-8. [CrossRef] 